\title{
Makeup Lifestyles of the Female Youths in Ghana. Evidence from Kumasi and Accra Tertiary Institutions
}

\author{
Solomon Ayesu Marfo, Peggy Maansah Ankai Howard ${ }^{1}$ Sylvia Asheley Akrong ${ }^{2}$ \\ Kweku Bedu Simpson ${ }^{3 *}$ \\ 1. Faculty of Creative Arts and Technology, Kumasi Technical University, P. O. Box 854, Kumasi-Ghana. \\ 2. School of Fashion and Design, Blue Crest College, Accra-Ghana. \\ 3. Department of Architectural Drafting, Accra Technical Training Centre, P. O. MB 177, Accra- Ghana.
}

\begin{abstract}
Women would want to appear more attractive and feminine to enjoy the benefits that accompany it. It is against this background that they predominate in makeup usage. The study fundamentally determined the makeup lifestyles of the female youths in selected tertiary institutions in Ghana. Employing descriptive research through cross sectional survey and using convenience sampling techniques, data were collected from female students, mainly in Accra and Kumasi tertiary institutions and 260 questionnaires analyzed. Findings revealed that respondents generally used makeup for glamour, attractiveness, supporting their career, creativity, feeling confident and empowerment. More respondents applied makeup only on special occasions and mostly considered the complexion, skin tone, skin type, clothing, occasion and quality of the product before using it. Generally, respondents used makeup whilst going to 'lectures', 'on a date', 'to church', and 'to work'. Some did not use makeup at all on all occasions and more makeup users spent less than 15 minutes on all situations especially to 'lectures', ‘job interviews', 'church' and 'visit to friends'. Greater respondents 'sometimes' or 'once daily' touched up their makeups and many 'seldom' carried makeup item(s) for touch-ups mostly being lipstick, powder, and lipgloss. More respondents started makeup between 16 and 19 years and more viewed makeup to social situations as 'important' and that makeup enhances their self-appearance, and boost their consciousness. Respondents were satisfied without makeup than with makeup and majority were aware of the negative effects of makeup on human skin. The study recommends that makeup users be educated on the negative effects of color cosmetics so that they would be better informed in their application. This study is the first to have been conducted in Ghana and could be useful for the cosmetic industry, researchers and the academia.
\end{abstract}

Keywords: Attractiveness, makeup cosmetics, female youths, tertiary institutions, makeup lifestyle, Ghana. Definition of Terms

In this paper, makeup refers to cosmetic makeup and makeup cosmetics means colored cosmetics, makeup items, cosmetics and are thus used interchangeably.

DOI: $10.7176 / \mathrm{ADS} / 75-01$

Publication date: August $31^{\text {st }} 2019$

\section{Introduction}

Physical attractiveness refers to "The person's aesthetic appeal as a visual social stimulus" (Cash \& Cash, 1982), and "the more attractive the face, the longer and the more often people looked at" (Leder et al. 2016). For Cash \& Cash (1982), physical appearance influences visual perception, personality and perceived attractiveness, and other features concerning the face and body dictates how human beings select their significant others and friends. This can control a person's suitability for a position in work related circumstances, and can affect a good number of favorable factors. Females feel pressurized to appear attractive purposely for getting the benefits in their education, career and social life (Verbickaite 2017). Frevert \& Walker (2014) found that attractive people are perceived to be healthier, less likely to commit crime, more likely to win in elections, have better relationships, more powerful, look more intelligent and even have some benefits in employment since ones personality is influenced by the perception of ones looks.

Cosmetics are capable of creating exceptional facial stimuli by elaborating cues to sexual dimorphism (Etcoff et al. 2011). Fundamentally, cosmetics is to enhance the promotion of sex differences such that the faces of females look more feminine and so more attractive. Jones et al. (2015) found that "the luminance contrast pattern of the eyes and eyebrows is consistently sexually dimorphic across a large samples of faces with females possessing lower brow contrast than males and greater eye contrast than males" adding that women employ cosmetic makeup to enhance sexual dimorphism in respect of the brow and eye contrast as well as increasing contrast that reduce as they grow. Cosmetic products are applied to the body for beautifying, cleansing or improving appearance and enhancing attractive features (Singh 2010) and 'make up' constitutes one of the categories of cosmetics purposely for face beautification (Claeyssens 2009). On the whole, makeup stands for a form of feminine expression and this intensely arouses a particular feelings. Usually men are not expected to wear makeup, nevertheless, due to professional and social pressures, women feel obliged to adhere to beauty norms and therefore make themselves up (Buegeler 2015). 
Research has shown that makeup cosmetics enhance the ratings of women's facial attractiveness. For instance, the number of male drivers who stopped to offer ride went up because of female facial makeup and this was however different compared to female drivers (Guéguen \& Lamy 2013). Women's perceived age could be reduced by the use of makeup as this can correct the skin's color and show youthful skin properties (Lee et al. 2018). Improving physical attractiveness has been one of the commonest reasons for makeup usage in Western cultures. Exemplary, Cash \& Cash (1982) found that women express a more positive body image and self-image when they put up makeup as against when not wearing makeup. For Cash \& Henry (1995), almost 50 percent of women negatively evaluate their appearance and significantly evaluate their body dissatisfaction and that negative evaluations concerning body image and appearance of American women seem to have gone up over the years. As an example, 44 percent of American women population today feel not beautiful without applying makeup cosmetic and resultantly, no matter where they go, be it movies, gym, school, work, or even the beach, they have to make themselves up before leaving home (Narang 2013). The author revealed that attractiveness, femininity, and sexiness positively correlate with increased makeup usage. Studies have revealed that the continual application of makeup cosmetics involving spending time to make oneself beautiful has been the source of enjoyment and comfort for women (Stuart \& Donaghue 2011). Women may apply make up in a manner useful for their desired image and in their attempt to receive a job or win over people, they may choose to apply minimal makeup. Contrarily, women might impress the opposite sex on a date by wearing heavier makeup in order to appear more attractive, feminine, and sexy (Narang 2013).

Issues about facial makeup have been dealt with by many authors in the world, of which some have been already highlighted. However, extensive literature search has revealed that no study of this nature has been done in Ghana. This paper therefore investigates the makeup lifestyle of the female youths at the tertiary institutions of Ghana and its outcome will create awareness for the cosmetic industry and the makeup users including adding to literature for the use of the academia and other researchers who may find it useful.

\subsection{Objectives}

The study determined the following:

- Reasons for wearing makeup.

- The extent to which female youth attach importance to makeup usage.

- Degree of overall happiness 'with' and 'without' make-up.

- Awareness of makeup effect on human skin.

\subsection{Hypothesis}

- There is significant difference among the various age divide in relation to the cosmetics carried for touch ups.

- Significant association exists between frequency of wearing facial makeup and frequency of carrying makeup for touchups.

- There is no significant difference among the various age brackets of the respondents regarding the overall face feature with makeup.

- There is no significant difference existing among the various age brackets of the respondents regarding the overall face feature without makeup.

\section{Literature Review}

\subsection{Appearance and Benefits of Makeup Cosmetics}

Facial image concerns the satisfaction with the various areas of the face, encompassing the eyes, eyebrows, lips, cheeks, skin complexion, and the overall face. Otherwise, body image constitutes the feelings and attitudes people experience toward their own appearance (Cash \& Henry, 1995). Cash et.al (2010) posit that physical appearance could be changed by individuals to manage and control their self and social images and there is beneficial impact of makeup on the perception of women's earning ability, professional class, health, and confidence. Due to that women can resort to cosmetic use to control their appearance and as they do, they may as well benefit from a boost in positive self-perception and well-being seemingly associated with makeup usage. Nash et.al. (2006) were of the view that feeling confident about one's appearance promotes social interactions especially for recruitment opportunities where creating first impression is vital. Jung \& Lennon (2003) have established strong positive relationships between body image and self-esteem and self-confidence. Narang (2013) researched into the psychological factors that affect makeup usage and the perception of makeup in different situations and concluded that attractiveness, femininity, and sexiness positively correlate with increased makeup usage. For Korichi et al. (2008), makeup serves as stimulant to our touch, smell and sight and functionally, it is for camouflaging and seduction. It is a holistic technique not only modifying one's appearance but facilitates in addressing self-image, emotions and mood as well. It can thus be seen as a daily routine either increasing positive or reducing negative 
affects about self-image and ones relation to the social environment.

\subsection{Makeup Cosmetics and their Functions}

Essentially, there are many colored cosmetics in use today and this may include lipstick, foundation / concealers, lip primers, mascara, eyeliner and lip liner. Others are bronzer, eyebrow pencil, blush and many others. Lipstick is a colored cosmetic used to apply color, texture and also to protect the lips (en.wikipedia.org). According to Kobayashi et al. (2017), lip stick can have influence on the perceived lightness of the facial skin and is said to be the major factor that decides how the face becomes attractive and the sex characteristics (Stephen \& McKeegan, 2010) as well as defining clearly the difference between the lip and the facial skin leading to an increased perceived health, womanhood and attraction (Jones et al. 2015; Russell 2003, 2010). The colors of lipstick can change the perceived skin color of the face (Kobayashi et al., 2017). To Ogilive et al. (2011), women importantly apply lipstick in a manner responsive to their daily variations in moods and identity and that this cosmetic type has been the accepted fashion discourse. Lipsticks like lip stain, lip liner, and lip gloss add color, tone and texture to the lips and studies have shown that first timers in makeup usage usually go for lipstick. In order to keep the applied lip stick boldly in place for a longer period, lip primer is necessary. Foundations and concealers in the form of powders or pastes are employed to cover unevenness of the skin, namely: pores, discolorations, pigment spots, injuries and blemishes to reduce the unevenness of skin's color (Mulhern et al. 2003; History of Cosmetics 2019) and undoubtedly causes the color to be closer to population average. When applied, it enables the skin to absorb better and hold over a long period of time other cosmetic products applied. Naturally, women have more color differences around their eyes, and to enhance the eyelashes so as to make them look more attractive, the use of mascara is necessary (History of Cosmetics 2019). Eyeliner as a makeup product is applied across the lash line, the area of the eye that grows eyelashes for the purpose of attractiveness. Additionally, eye shadow serves the same purpose as the eyeliner and the mascara and their use make wearers appear younger. Research conducted by Matsushita et al. (2015) showed that both eyeliner and mascara cause the eyes to appear bigger than the reality by up to $6 \%$ (13\% in area), nonetheless, their effects are non-additive. Eyeliner causes the perceived eye size to increase only when mascara is absent. In situations where mascara is used, eyeliner has no additional effect and that eye shadow increases perceived eye size by about 5\% (10\% in area). Lip liner provides a great outline for the lipstick, make good the asymmetrical areas on the upper or lower edges of the lips, making them appear fuller, rounder, or even plumper, and minimizing feathering. Bronzer and blush give a little color and glow to the complexion. They highlight the cheekbones, and make the wearer look healthy and vital (Wikipedia.com). The use of blush causes excitement since for many, it looks like their natural color in sexual mood (https://www.scienceofpeople.com/makeup/). Eyebrow pencil makes more prominent, shapes and changes the perceived position of eyebrows and increase of contrast. It makes thin eyebrows appear noticeable, strong and beautiful and sharpens weak arches; fills in patchy or run thick-to-thin brows and resurfaces scars as a result of a cut or acne (www.makeupartistessentials.com/an-introduction-to-makeup-types-of-makeup/; https://en.wikipedia.org/wiki/Primer(cosmetics). Contouring also enables more symmetrical and additionally sharpens the angles (https://www.scienceofpeople.com/makeup/).

\section{Design /Methodology/ Approach}

The study's primary data was collected using questionnaires administered by the researchers at the colleges and universities mainly in Accra and Kumasi metropolises. The study was conducted between February and May 2019, and data was gathered on variables concerning the importance and make up lifestyle of the female youth in the tertiary institutions within the study areas.

The study basically employed descriptive research (Isaac \& Michael 1995) and applied cross sectional survey to collect data in order to make inferences about the population at that point in time (Lavrakas 2008). Convenience sampling techniques (Dörnyei 2007) was employed in the data collection from the 309 students from the various tertiary institutions contacted. The questionnaires had a preamble spelling out the rationale for the study as well as a statement assuring respondents of the necessary confidentiality and anonymity deserved (Frankael \& Wallen 2003). Though the instrument was taking through the test of validity and reliability, opportunity was offered for clarification and explanations to the respondents who needed help. Respondents used between 20 and 25 minutes to complete one questionnaire. The questionnaire data covered (1) Bio data /personal records (e.g. gender, age, current educational level, name of institution and program offered), (2) reasons for wearing makeup, (3) frequency of makeup usage (4) factors influencing make-up usage (5) importance attached to makeup situations (6) time spent on make-up application (7) degree of happiness 'with' and 'without' make-up and (8) awareness of the effect of makeup cosmetics. Questionnaire items were adapted from the literature (For example, Verbakaite 2017; Ditch the Label 2017; Britton 2012; Korichi et al. 2008). Appropriate Likert scale types were employed to gather the data. For example, 5 -points Likert scale type ranging from 'strongly disagree' to 'strongly agree' was used to find out the motivating reasons for wearing makeup whereas another 5 -points Likert scale type was used to establish the frequency of makeup usage. In exploring the factors influencing make-up usage, 3-point Likert scale from 'not 
at all' to 'great extent' was applied. To ascertain the various makeup situations and the appropriate makeup cosmetics used, make up situations ranging from 'lectures' to 'market' and cosmetics ranging from 'foundation' to 'no makeup' were employed. Establishing the time spent on make-up application, scale type ranging from 'none' to 'over an hour' helped in eliciting the information. To know the number of times in a day respondents usually touch-up their make-ups, Likert scale type from 'never' to ' 5 or more' was used, and how often respondents do carry make-up with them in order to touch-up, 'never' to 'always' was also applied. Options such as 'mascara' through to 'blemishing corrector' assisted in determining the cosmetic type usually carried for makeup touch ups. For the age at which respondents first started wearing make-up to be known, scale ranging from 'under 12 years' to '24 years and above' was appropriate. Respondents were also asked to rate the importance of given statements ranging from 'wearing make-up in public' to 'wearing make-up to enhance self-appearance', and Likert scale type from 'unimportant' to 'very important' was used. In ascertaining the degree of happiness 'with' and 'without' make-up, 'unhappy' to 'very happy' was employed. The awareness of the side effects of makeup cosmetics was determined using 'not sure' to 'sure' whereas 'strongly disagree' to 'strongly agree' was employed to verify if cosmetics usage have negative effect on the user's skin.

With the use of the SPSS software version 22, the survey data was analyzed using descriptive statistics (i.e. frequency, mean, standard deviation) and mean response analysis was used to rank the responses. Inferential statistics such as chi- square was applied to verify the statistical association between frequency of wearing facial make up and frequency of carrying makeup cosmetics for touchups whilst Kruskal -Wallis test helped to establish the statistical difference among the various age divide in relation to frequency of cosmetics carried for touch ups as well as the overall face feature 'with' makeup and also 'without' makeup using 'p' value of 0.01 (Hinton 2004).

\section{Result / Findings}

4.1 Questionnaire Analysis

320 questionnaires were administered and 309 were returned. $49(15.9 \%)$ out of the returned questionnaires were rejected because they were not completely filled. Therefore $260(84.1 \%)$ were used for the analysis. The Cronbach alpha value for the 82 questionnaire items was 0.7 indicating that the items were moderately reliable (Hinton 2004).

\subsection{Characteristics of the Respondents}

All respondents were female and majority (97.3\%) fell between the ages of 18 and 35 years with 18 to 25 years forming $76.2 \%$, meaning almost every respondent was within the youth bracket. These respondents were drawn from the tertiary institutions such as Kumasi Technical University (43.8\%), Accra Technical University (18.8\%), Kwame Nkrumah University of Science and Technology (18.1\%), Blue Crest College (16.2\%) and other institutions (3.1\%). Predominantly, (93.1\%) of respondents' current educational status was either HND or at the Bachelor level with the remaining catering for Masters or Advance Diploma. Respondents' program offered composed of Fashion (62.3\%), Textiles (11.2\%), Purchasing and Supply (8.5\%), Marketing (6.2\%), Metal design $(1.9 \%)$, Accountancy (1.5\%), Industrial Arts (1.2\%), Hospitality management (1.2\%), Communication design $(2.3 \%)$ and Management (1.2\%). Other programs like Ceramics, Human Resource, Banking and Finance, Political Science, and Art and Culture only formed (2.5\%). This result presupposes that respondents have the ability to contribute meaningfully to the study.

\subsection{Motivating Reasons for using Makeup}

It was important to verify the motivating reasons for facial makeup usage among the respondents since this might help in determining their makeup lifestyles. In Table 1, the top six reasons for facial makeup among the female youths /were to; make them feel glamorous (3.37 \pm 1.325$)$; attractive (3.03 \pm 1.423$)$; support their career

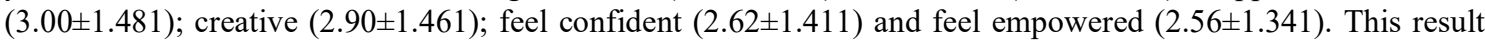
suggests that more student makeup users in the study areas wore facial makeup for the stated reasons. 
Table 1. Motivating Reasons for Makeup Usage

\begin{tabular}{lllllll}
\hline & \multicolumn{3}{l}{ Level of Agreement } & & \\
Reasons & No. & Min & Max & Mean & St. D & Rank \\
\hline Make-up makes me feel glamorous & 260 & 1 & 5 & 3.37 & 1.325 & $1^{\text {st }}$ \\
Make-up makes me attractive & 260 & 1 & 5 & 3.03 & 1.423 & $2^{\text {nd }}$ \\
Make-up supports my career & 260 & 1 & 5 & 3.00 & 1.481 & $3^{\text {rd }}$ \\
Make-up makes me creative & 260 & 1 & 5 & 2.90 & 1.461 & $4^{\text {th }}$ \\
Make-up makes me feel confident & 260 & 1 & 5 & 2.62 & 1.411 & $5^{\text {th }}$ \\
Make-up makes me feel empowered & 260 & 1 & 5 & 2.56 & 1.341 & $6^{\text {th }}$ \\
Make-up makes me self-conscious & 260 & 1 & 5 & 2.53 & 1.388 & $7^{\text {th }}$ \\
I use make-up to control the image of myself & 260 & 1 & 5 & 2.38 & 1.349 & $8^{\text {th }}$ \\
Make-up protects my skin from sunlight & 260 & 1 & 5 & 2.32 & 1.304 & $9^{\text {th }}$ \\
Make-up enable me to smile & 260 & 1 & 5 & 2.29 & 1.288 & $10^{\text {th }}$ \\
I feel sensual when I wear make-up & 260 & 1 & 5 & 2.27 & 1.239 & $11^{\text {th }}$ \\
I wear make-up always when am in contact with people & 260 & 1 & 5 & 2.19 & 1.242 & $12^{\text {th }}$ \\
Make-up makes me feel safe & 260 & 1 & 5 & 2.05 & 1.126 & $13^{\text {th }}$ \\
I use make-up to allure people & 260 & 1 & 5 & 2.03 & 1.238 & $14^{\text {th }}$ \\
Make-up makes me feel natural & 260 & 1 & 5 & 1.91 & 1.135 & $15^{\text {th }}$ \\
Without make-up, I don't like myself & 260 & 1 & 5 & 1.76 & 1.115 & $16^{\text {th }}$ \\
Without make-up, I am insipid & 260 & 1 & 5 & 1.75 & 1.086 & $17^{\text {th }}$ \\
\hline
\end{tabular}

\subsection{Extent of Importance Attached to Makeup}

4.4.1 Frequency of Makeup Usage

Determining how often respondents made up their faces was essential to the study as it will contribute to knowing their makeup lifestyles. The result in Figure 1 showed that most respondents $(65.8 \%)$ used facial makeup on 'special occasions', (16.2\%) 'everyday', (9.6\%) every week, (4.2\%) 'neutral' whilst the rest (4.2\%) either 'every two weeks' or 'not at all', suggesting that many students do not always depend on makeup for becoming attractive as it pertains elsewhere in America and Asia.

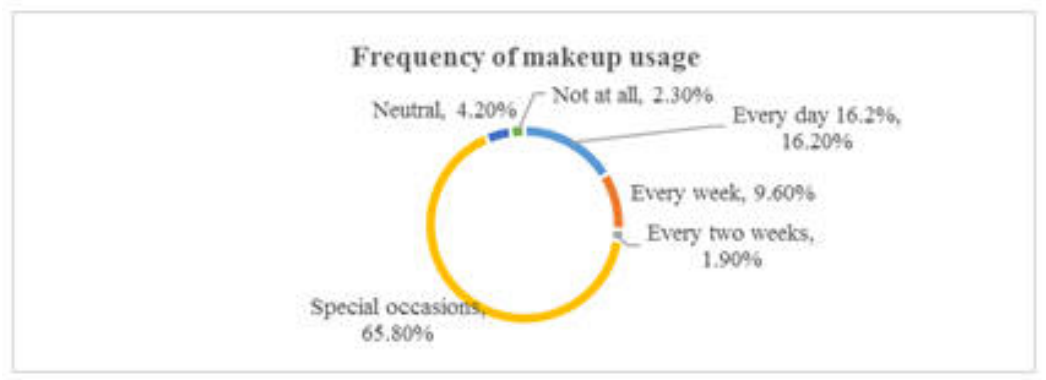

Figure 1. Frequency of Makeup Usage

4.4.2 Factors Influencing Makeup Usage

It was important to find out the considerations made by respondents before using makeup cosmetics. This will enable readers know how conscious makeup users were in their use of cosmetics. The result in Table 2 showed that more respondents to a 'moderate' or 'great extent' considered factors such as skin complexion (2.65 \pm 0.613$)$;

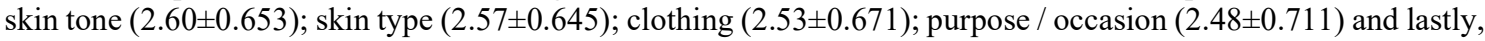
quality of the product $(2.44 \pm 0.757)$ before wearing makeup, indicative of the degree of their consciousness.

Table 2. Factors Influencing Makeup Usage

\begin{tabular}{lcccccc}
\hline & \multicolumn{7}{c}{ Extent of consideration } \\
Factors & No. & Min & Max. & Mean & St. D & Rank \\
\hline Complexion (dark, light skimmed etc.) & 260 & 1 & 3 & 2.65 & 0.613 & $1^{\text {st }}$ \\
Skin tone (even, dark, spots on cheek etc.) & 260 & 1 & 3 & 2.60 & 0.653 & $2^{\text {nd }}$ \\
Skin type (sensitive, dry, oily, normal combination) & 260 & 1 & 3 & 2.57 & 0.645 & $3^{\text {rd }}$ \\
Clothing & 260 & 1 & 3 & 2.53 & 0.671 & $4^{\text {th }}$ \\
Purpose / occasion & 260 & 1 & 3 & 2.48 & 0.711 & $5^{\text {th }}$ \\
Quality of the product (i.e. whether fake or original) & 260 & 1 & 3 & 2.44 & 0.757 & $6^{\text {th }}$ \\
\hline
\end{tabular}

Key: 1= Not at all; 2= Moderate; $3=$ Great extent 
4.4.3 Makeup Situations and the Appropriate Makeup Cosmetics Applied

The study also found it necessary to investigate the various places / situations where respondents wore or should wear makeup to and the appropriate makeup items applied. This in effect will enable their makeup lifestyles to be known. Therefore Table 3 is the illustration of the results of the decorative makeup cosmetics (like foundation, bronzer, powder, eye brow pencil/eye brow shadow, eye pencil, mascara, lip primer, lip stick and lip-gloss) respondents do apply for facial makeups in situations (such as to lectures, work, job interviews, date, club, visiting a friend, to church, to festival and to market). On the whole, $86.1 \%$ applied makeup cosmetics across all the makeup situations as against $13.9 \%$ without makeup. Furthermore, more respondents applied makeup cosmetics 'to lectures', 'on a date', 'to church' and then 'to work' in that order. Less respondents made up their faces whilst going to the market than all the other circumstances. Moreover, on the average, foundation was used more (57.8) across all make up situations, followed by finishing powder (51.9), eye brow pencil (46.9), lipstick (45.1), lip gloss (44.9) and then mascara (40.9) in that order with lip primer (25.8) being the least used.

Table 3. Makeup Situations and Appropriate Makeup Cosmetics Applied

\begin{tabular}{|c|c|c|c|c|c|c|c|c|c|c|c|c|c|c|}
\hline \multirow{2}{*}{$\begin{array}{l}\text { Makeup } \\
\text { situations }\end{array}$} & \multicolumn{14}{|c|}{ Number of counts / \% per makeup cosmetics used vs. no makeup } \\
\hline & 1 & 2 & 3 & 4 & 5 & 6 & 7 & 8 & 9 & 10 & $\begin{array}{l}\text { Total } \\
\text { freq. }\end{array}$ & 11 & $\begin{array}{l}\% \\
\text { makeup }\end{array}$ & $\begin{array}{l}\% \text { no } \\
\text { makeup }\end{array}$ \\
\hline $\begin{array}{l}\text { To class / } \\
\text { Lectures }\end{array}$ & 80 & 32 & 53 & 56 & 28 & 40 & 41 & 32 & 57 & 69 & 488 & 38 & 92.8 & 7.2 \\
\hline To work & 57 & 30 & 57 & 52 & 26 & 36 & 48 & 33 & 48 & 55 & 442 & 54 & 89.1 & 10.9 \\
\hline $\begin{array}{l}\text { To a job } \\
\text { interview }\end{array}$ & 53 & 19 & 67 & 37 & 30 & 27 & 48 & 24 & 38 & 54 & 397 & 56 & 87.6 & 12.4 \\
\hline On a date & 64 & 38 & 49 & 50 & 41 & 44 & 43 & 31 & 42 & 45 & 447 & 34 & 92.9 & 7.1 \\
\hline To club & 50 & 34 & 55 & 48 & 38 & 43 & 42 & 28 & 41 & 26 & 405 & 71 & 85.1 & 14.9 \\
\hline $\begin{array}{l}\text { Visiting a } \\
\text { friend }\end{array}$ & 52 & 23 & 37 & 44 & 26 & 34 & 31 & 20 & 42 & 44 & 353 & 79 & 81.7 & 18.3 \\
\hline To church & 60 & 36 & 59 & 60 & 24 & 35 & 51 & 25 & 50 & 45 & 445 & 42 & 91.4 & 8.6 \\
\hline To festival & 54 & 23 & 62 & 48 & 25 & 40 & 41 & 19 & 60 & 47 & 419 & 69 & 85.9 & 14.1 \\
\hline To market & 50 & 16 & 28 & 27 & 10 & 16 & 23 & 20 & 28 & 39 & 257 & 118 & 68.5 & 31.5 \\
\hline Total & 57.8 & 27.9 & 51.9 & 46.9 & 27.6 & 35 & 40.9 & 25.8 & 45.1 & 47.1 & 406 & 62.3 & 86.1 & 13.9 \\
\hline
\end{tabular}

Key: $1=$ foundation; $2=$ bronzer; 3 =finishing powder; $4=$ eye brow pencil/shadow; $5=$ eye shadow

$6=$ eye pencil/ liquid eyeliner; $7=$ Mascara; $8=$ lip primer /lip liner; $9=$ lip stick/liquid lipstick

$10=$ lip gloss; $11=$ No make up

NB: missing numbers are not included

\subsubsection{Time Spent on Makeup Situations}

Knowing the duration within which respondents make up, was also crucial to the study as this might provide a clue for determining their makeup lifestyles. Hence in Table 4, more respondents $(34.7 \%)$ spent no time on all situations because they were not makeup users. Whereas, 33.6\% spent less than 15 minutes on all makeup situations, $16.4 \%$ spent between 15 and 30 minutes with the rest $(15.24 \%)$ using more than 30 minutes to make up their faces in all make up situations. With more people using 30 minutes or less on all make up situations may imply that they did not depend on elaborate make up for enhancing their beauty. The result further depicts that in less than 15 minutes duration, $52.2 \%$ spent it on applying makeup 'to lectures', 'job interview' (41.5\%), 'to church' $(39.6 \%)$ and then to 'visit a friend' $(37.3 \%)$ as compared to the other makeup circumstances. Comparably, between 15 and 30 minutes duration, more respondents $(27.7 \%)$ spent that time 'on a date', followed by 'job interview' $(22.4 \%)$ 'to church' $(21.2 \%)$ and 'to club with friends' $(21.2 \%)$ meaning the students did not use elaborate makeup to the stated circumstances. More so, most respondents $(66.9 \%)$ neither made up whilst going 'to the market' nor 'at home' $(63.1 \%)$. This might mean that many students whilst at home or to the market would like to maintain their natural faces. On the whole, these findings point to the conclusion that most tertiary students in the study areas were either light makeup users or do not makeup at all. 
Table 4. Time Spent on Makeup Situations

\begin{tabular}{|c|c|c|c|c|c|c|c|}
\hline \multirow[b]{2}{*}{ Makeup Situations } & \multicolumn{7}{|c|}{ \% Time Spent } \\
\hline & 1 & 2 & 3 & 4 & 5 & 6 & Total \\
\hline Spending the day at home & 63.1 & 25.8 & 3.8 & 2.6 & 1.2 & 3.5 & 100 \\
\hline To lectures & 28.5 & 52.2 & 13.5 & 3.8 & 0.8 & 1.2 & 100 \\
\hline To a job interview & 24.2 & 41.5 & 22.4 & 5.4 & 3.8 & 2.7 & 100 \\
\hline To church & 20.8 & 39.6 & 21.2 & 9.2 & 4.6 & 4.6 & 100 \\
\hline On a date & 13.5 & 25.8 & 27.7 & 14.6 & 9.6 & 8.8 & 100 \\
\hline To club / bar with friends & 28.8 & 28.8 & 21.2 & 10 & 5.0 & 6.2 & 100 \\
\hline To visit a friend & 37.3 & 37.3 & 12.7 & 6.2 & 2.3 & 4.2 & 100 \\
\hline To a festival & 29.6 & 31.5 & 18.4 & 10.4 & 5.4 & 4.7 & 100 \\
\hline To market & 66.9 & 20.1 & 6.5 & 2.7 & 1.9 & 1.9 & 100 \\
\hline \% Average Total & 34.7 & 33.6 & 16.4 & 7.2 & 3.84 & 4.2 & 100 \\
\hline
\end{tabular}

Key: $1=$ None; $2=$ Less than 15minutes; $3=15-30$ minutes; $4=31-45$ mins; $5=46-60$ minutes.

\subsubsection{Frequency of Makeup Touchups}

Verifying the frequency of makeup touchups of the respondents (Figure 2), frequency of carrying items for touchups (Figure 3 ) and the items normally carried for that purpose (Table 5) was also necessary in an attempt to investigate their makeup lifestyles. Figure 2 displays that about $50 \%$ of the respondents 'rarely or once daily' did touch up their makeups, followed by 'never' $(25.4 \%)$ and the remaining (25\%) 'More than once a day'.

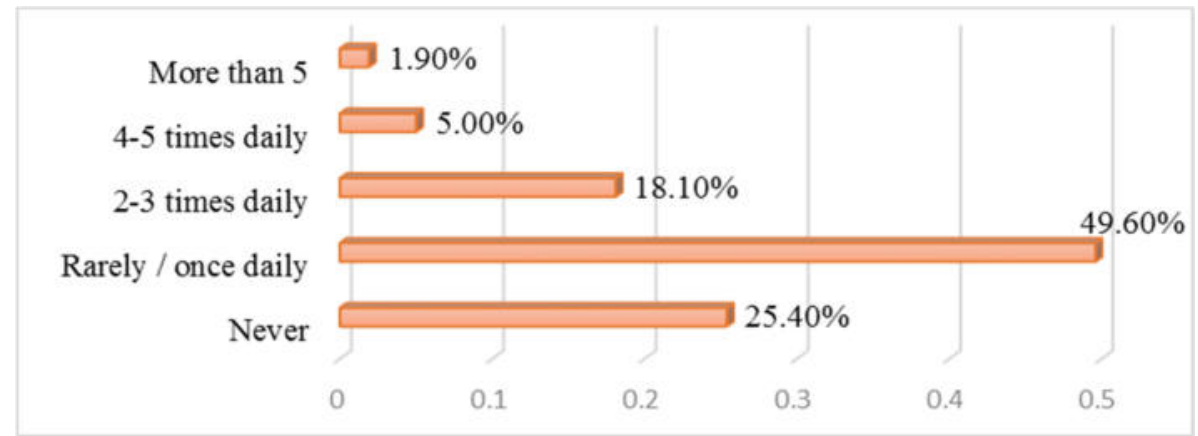

Figure 2. Frequency of Makeup Touchups

4.4.6 Frequency of Carrying Makeup Cosmetic(s)

More respondents (55.8\%) 'Seldom', (27.3\%) 'Always' and (16.9\%) 'Never' carried make up cosmetic(s) in their bags for touch ups (Figure 3).

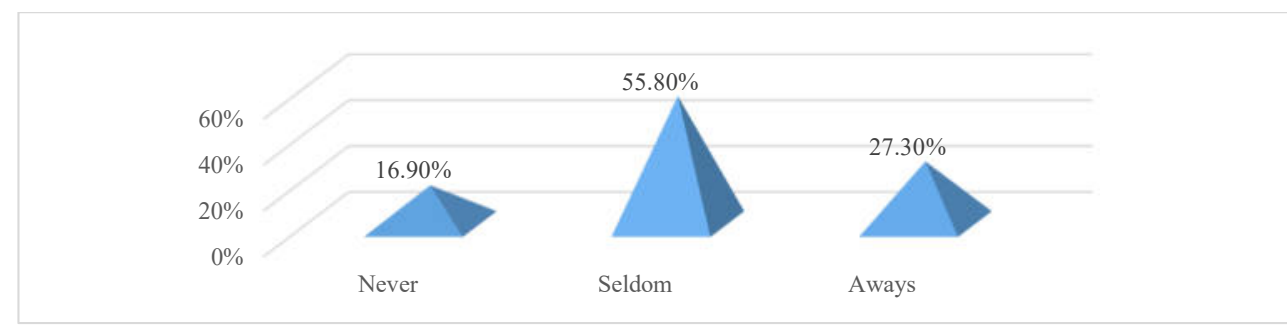

Figure 3. Frequency of Carrying Makeup Cosmetic(s)

The quantum of respondents who touched up their makeups 'rarely' or 'once daily' (Figure 2) appears to be a reflection of the number of the respondents who seldom carried makeup for touch ups (Figure 3).

The result in Table 5 depicted that lipstick (69), powder (52) and lip gloss (49) were the three most carried makeup items for touch ups, perhaps they have a short sticky period. Based on the result in Table 5, the Kruskal Wallis Test $\left(\chi^{2}=16.370 ; \mathrm{df}=4 \mathrm{p}<0.05\right)$ indicates a significant difference among the various age divide in relation to the frequency of cosmetics carried for touch ups and therefore supports the hypothesis. Performing chi square test, the study further established a significant association between the frequency of carrying makeup for touchups and frequency of wearing facial make up $\left(\chi^{2}=54.960, \mathrm{df}=4, \mathrm{p}<0.01\right)$ and thus confirms the hypothesis. 
Table 5. Result of Makeup Items for Touchups

\begin{tabular}{lcclccccccc}
\hline $\begin{array}{l}\text { Make } \\
\text { up type }\end{array}$ & Mascara & $\begin{array}{l}\text { Eye } \\
\text { Liner }\end{array}$ & $\begin{array}{l}\text { Liquid } \\
\text { Eyeliner }\end{array}$ & $\begin{array}{l}\text { Eye } \\
\text { Shadow }\end{array}$ & $\begin{array}{l}\text { Lip } \\
\text { Stick }\end{array}$ & $\begin{array}{l}\text { Lip } \\
\text { Gloss }\end{array}$ & Foundation & Powder & Blush & $\begin{array}{l}\text { Blemishing } \\
\text { Corrector }\end{array}$ \\
\hline $\begin{array}{l}\text { Counts } \\
\text { \% }\end{array}$ & 31 & 41 & 17 & 26 & 69 & 49 & 26 & 52 & 17 & 14 \\
\hline
\end{tabular}

\subsubsection{Age of Starting Makeup}

Once again, it was in place to know the age at which respondents first started facial makeup as far as the study was concerned. Consequently, majority (82.6\%) either began makeup between the ages of (16-19) or (20-23) or above 24 years (Figure 4$)$.

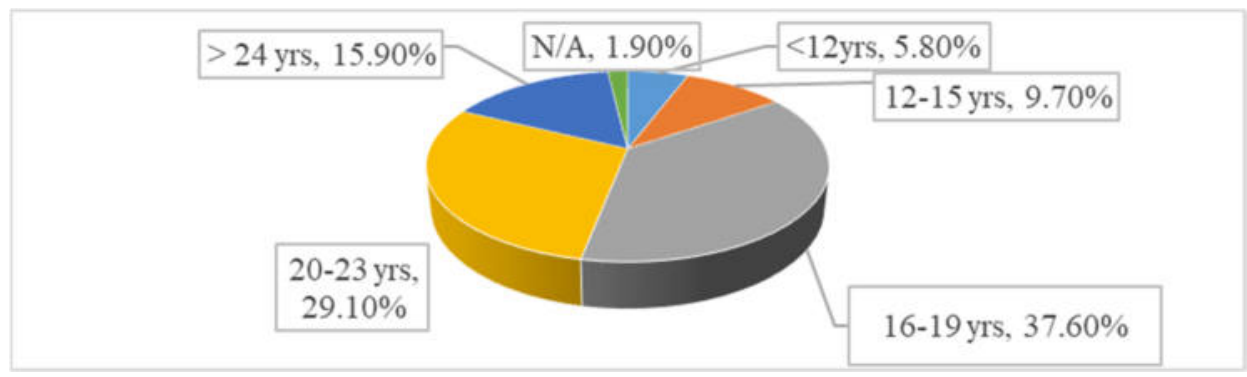

Figure 4. Age of Starting Makeup

\subsubsection{Importance of Wearing Makeup to Situations}

The opinion of the respondents regarding how important it was to wear facial makeup to the given situations was necessary for the study. Resultantly, Table 6 revealed that less than $50 \%$ opined that wearing makeup to the stated situations was either 'important' or 'very important'. Zeroing in on the individual circumstances, the result indicated that it was either "important" or "very important" to wear makeup 'on a date' (60\%), 'in other social situations or gatherings' $(51.3 \%)$, 'to enhance self-appearance' $(47 \%)$, 'to job interview' $(41.1 \%)$, 'to enhance self-confidence' (33.9\%), and 'to lecture' (28\%), implying that looking attractive 'on a date' appears to be more important to respondents than the other situations.

Table 6. Opinions about the Rate of Importance of Wearing Makeup

\begin{tabular}{lcccccc} 
& \multicolumn{2}{c}{ \% Degree of Importance } & & & Total \\
Statement & 1 & 2 & 3 & 4 & 5 & 100 \\
\hline Wearing make-up in public & 27.3 & 20.4 & 22.3 & 23.1 & 6.9 & 19.2 \\
Wearing make-up to job interview & 15 & 25.8 & 18.1 & 21.9 & 100 \\
Wearing make-up to work / lecture & 21.9 & 24.6 & 25.4 & 18.8 & 9.2 & 100 \\
Wearing make-up in other social situations & 8.8 & 17.3 & 22.3 & 29.2 & 22.3 & 100 \\
Wearing make-up on a date & 6.5 & 14.6 & 18.8 & 27.3 & 32.7 & 100 \\
Wearing make-up to enhance self confidence & 25 & 21.5 & 19.6 & 18.5 & 15.4 & 100 \\
Wearing make-up to enhance self-appearance & 16.9 & 18.1 & 18.1 & 23.5 & 23.5 & 100 \\
Total & $\mathbf{1 7 . 3}$ & $\mathbf{2 0 . 3}$ & $\mathbf{2 0 . 7}$ & $\mathbf{2 3 . 2}$ & $\mathbf{1 8 . 5}$ & $\mathbf{1 0 0}$ \\
\hline
\end{tabular}

Key: $1=$ Unimportant; $2=$ Somewhat Important; $3=$ Neutral; $4=$ Important; $5=$ Very Important 
4.5 Overall Face Features 'with' and 'without' Makeup

The extent to which respondents were satisfied 'with' and 'without' makeup was very crucial to study. This shows the degree to which they depend on makeup for attractiveness. In Table 7, the result revealed that overall, a chunk of the respondents $(55.8 \%)$ were either 'happy' or 'very happy' 'without' wearing makeup as against (39.6\%) 'With makeup' on their faces. This may imply that many respondents did not depend on makeup in order to enhance their attractiveness (Table 7). The Kruskal Wallis Test result $\left(\chi^{2}=13.714\right.$; $\left.\mathrm{df}=4 \mathrm{p}>0.01\right)$ suggests no significant difference among the various age brackets of the sample regarding overall face feature 'with makeup' confirming the hypothesis. Nonetheless, significant difference exists in respect of the overall face feature 'without makeup' $\left(\chi^{2}=13.704 ; \mathrm{df}=4, \mathrm{p}<0.01\right)$ hence throwing out the hypothesis.

Table 7. Overall Face Features With and Without Makeup

\begin{tabular}{lccccccc}
\hline & & \multicolumn{4}{c}{ \% Level of happiness } & & \\
Face features with and without makeup & $\mathbf{1}$ & $\mathbf{2}$ & $\mathbf{3}$ & $\mathbf{4}$ & $\mathbf{5}$ & Total \\
\hline Without makeup & 7.7 & 13.8 & 22.7 & 28.1 & 27.7 & 100 \\
With makeup & 16.2 & 15.4 & 28.8 & 22.3 & 17.3 & 100 \\
Kruskal Wallis Test result: & Overall face feature 'without makeup' $\left(\chi^{2}=13.704 ; \mathrm{df}=4 \mathrm{p}<0.01\right)$ & & \\
& Overall face feature 'with makeup' $\left(\chi^{2}=13.714 ; \mathrm{df}=4 \mathrm{p}>0.01\right)$ & & \\
\hline
\end{tabular}

Key: $1=$ Unhappy; $2=$ Somewhat Happy; $3=$ Neutral; $4=$ Happy; $5=$ Very Happy

\subsection{Awareness of Effects of Makeup Cosmetics}

Having studied their makeup lifestyles, there was also the need to know whether they were aware of the negative effects of makeup cosmetics on their skin or not. It was discovered that whilst majority $(70 \%)$ of respondents were sure of their awareness of the negative effects of makeup cosmetics, $(30 \%)$ were either not sure or undecided (Figure 5). This result is a reflection of the result in Figure 6 showing that a large proportion of the respondents $(71.15 \%)$ either 'agree' or 'strongly agree' that makeup cosmetics could have negative effect on the users' skin.

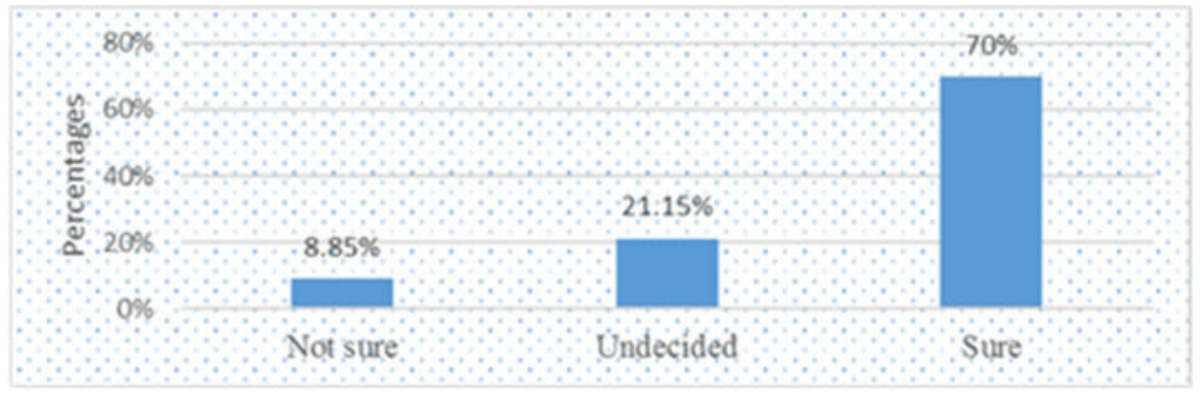

Figure 5. Awareness of Effect of Makeup Cosmetics

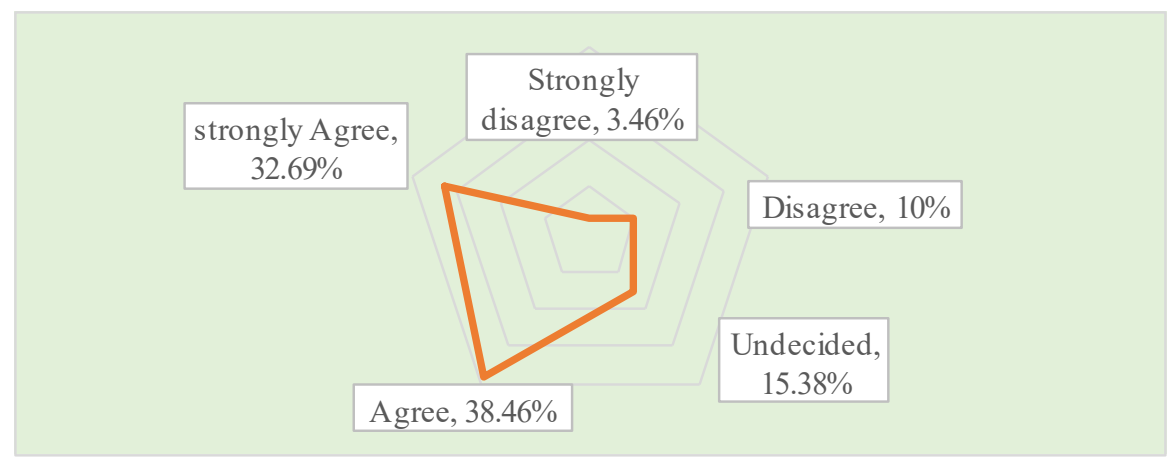

Figure 6. Negative Effect of Makeup Cosmetics on Users' Skin

\section{Discussion of Findings}


Findings have so far shown that people used makeup for varied reasons. Whilst our findings point to the top six reasons for makeup use being for glamour, attractiveness, career support, creativity, confidence, and empowerment, (Table 1), Korichi et al. (2008) reported that most people used makeup in the evening to allure and that more people wore makeup whilst in public and that over $80 \%$ felt insipid without makeup. Arguably, the motive for people applying makeup cosmetics in public might be attributed to similar reasons as highlighted in the study therefore on this score, the findings might not be different. However, more people according to Korichi et al. (2008) applying makeup for alluring in the evening, appears to be contrary to our findings which indicates that less respondents did it for that same reason. Similar study conducted by Ditch the Label in partnership with Sleek Makeup (2017) pinpointed that more people make up for attraction, creativity, safety, and confidence among others. The study thus believes that generally, people makeup their faces for similar reasons as enumerated above irrespective of the geographical differences.

In respect of the extent of importance attached to makeup, the study considered factors such as frequency of makeup usage, duration of makeup application, frequency of makeup touch ups, frequency of carrying makeup items, makeup items mostly carried for touch ups, age at which makeup was first applied, and the most important situations where makeup should be used. Whilst more respondents in Ghana used makeup on special occasions in order to enhance their beauty (Figure 1), more people in America and Asia always depended on makeup for attraction. Our findings also pointed to more student makeup users considering the skin complexion, skin tone, skin type, clothing, occasion and quality of the product before applying makeup cosmetics (Table 2). For Paawanee (2015), factors like skin type, age, outfit, and occasion should be considered before using makeup. Basically, it is important that such factors are critically looked at in view of the effects of makeup and so if more people consider that then it is good. Moreover, the clothing people intend wearing influence their makeup usage in that makeup serves a complementary role in using clothing in order to develop and make complete a look (Guthrie et al. 2008) hence our findings support the authors above. Again, as our findings revealed that more people made up their faces to lectures than any other makeup situations, Verbakaite (2017) found that going to club was the place where most people makeup to, whereas, Britton (2012) also reported that majority of the America College students were likely to makeup on 'a date' than in all other makeup situations. This might mean that due to individual and geographical differences, preference for makeup to makeup situations varies from country to country. Not only this, mascara was adjudged the most makeup item used in all makeup situations by the Caucasians (Verbakaite 2017). In similar manner, the study of America College students also showed similar result (Britton 2012) making it different from our findings which revealed that rather, it was foundation that was mostly used by respondents across all the various makeup situations (Table 3). The result of the duration in which respondents usually applied facial makeup on the different makeup situations in the study areas also differed from what is in related literature. Whereas this paper recorded more respondents spending between 15 and 30 minutes for applying makeup 'on a date' than to 'job interview', or 'to church' or 'to the club' (Table 4), Verbakaite (2017) reported that majority of the Caucasian women spent similar duration on makeup for 'job interviews' followed by 'on a date' and then 'to club with friends'. Britton (2012) found most American College students spending between 10 and 20 minutes on 'a date' and this is also not in line with any of the findings presented in this paper in that whilst majority of the college students used 10 to 20 minutes for makeup on a date, this study recorded between 15 and 30 minutes for that purpose. The variations in the findings might be due to geographical, demographic and individual differences. In respect of the frequency of makeup touch ups, and frequency of carrying makeup items for touch-ups, about half $(49.6 \%)$ of the respondents 'rarely or once daily' touched up their makeups as compared to the others (Figure 2) and close to $56 \%$ of makeup users seldom carried makeup items for touch ups as against the others (Figure 3). This may be explained that many of the students were not so much into makeup use and therefore were not addicted. Lip stick, powder and lip gloss were the most popular makeup items carried for touch-ups (Table 5) perhaps they have less sticky duration than the others. In the case of the American College students, Britton (2012) found that mascara was used most followed by eye liner, lip gloss and then powder. Clearly the two findings seem to vary and this might be as a result of geographical, demographic and individual differences. In connection with the age at which respondents began to apply makeup cosmetics, more Caucasian participants started makeup between the ages of 10 and 21 years (Verbakaite 2017), contrary to more American College students beginning at the ages between 12 and 15 years (Britton 2012). Once again, the findings in Figure 4 (i.e. more respondents beginning makeup between the ages of 16 and 19 years) do not support the findings of the authors above, meaning more Caucasians and Americans start wearing makeup earlier than their Ghanaian counterparts. This probably may be owing to the geographical, demographic, peer influence and other factors that might be at variance with that of Ghana. In Verbakaite (2017)'s findings, the most important situation where makeup was used was when attending job interviews, whereas the findings in this paper have shown otherwise. That is, the most important situation to wear makeup to was whilst 'on a date', (Table 6), suggesting that respondents in Ghana believed that they should look more attractive on 'a date' than to 'job interviews'. The dichotomy of the findings may be attributed to how respondents valued the various makeup situations which in effect influenced their makeup lifestyles. 
The overall face features of respondents 'with' and 'without' makeup showed that $55.8 \%$ were satisfied with their faces without makeup than with makeup (39.6\%) indicative of the fact that many respondents did not depend on makeup in order to be attractive (Table 7). This outcome is in sharp contrast to the findings of Verbakaite (2017) who established that majority of the Caucasian participants were of the opinion that decorative cosmetics did improve female perception of their own face features.

Findings further established that more respondents were sure of the effect of makeup (Figure 5) and admitted that makeup cosmetics could have negative effect on the human skin (Figure 6). Apparently, some of these side effects might be skin irritation, allergies, infections, headaches, skin cancer, hair problems, acne, infertility, premature ageing, hormonal imbalance and many more (Daily Hunt 2015) and it is thus important that users and potential users are made aware of, so as to make informed decisions about its use.

\section{Conclusion}

The paper investigated the makeup lifestyles of the female youths in the tertiary institutions of Ghana. In so doing, extensive literature was reviewed to establish the relevant underpins for the study. Through cross sectional survey and with convenience sampling techniques, data were collected from 309 respondents out of which 260 were analyzed.

Findings suggested that most respondents applied makeup mostly for glamour, attractiveness, career support, creativity, confidence, empowerment and self-consciousness. Majority of the respondents used facial makeup on special occasions and many considered mainly, factors such as complexion, skin tone, skin type, the dress, purpose of the occasion and quality of the product before using cosmetic makeup. Almost $14 \%$ of the respondents did not have interest in makeup usage and the rest used varied makeup cosmetics depending on the makeup situation. Respondents usually wore makeup to 'lectures', 'work', 'job interviews', 'on a date', 'to club', when 'visiting friends', and to 'church' and in all these circumstances, foundation was mostly used followed by powder, lip gloss, lipstick, eye brow pencil/shadow and mascara. Most makeup wearers normally spent less than 15 minutes to make up their faces. Respondents 'rarely or once daily' did makeup touch ups and most seldom carried makeup item(s) for that purpose. Generally, lipstick, powder, lip gloss, eye liner and mascara in that order were mostly carried for touch ups. Significant association was established between how often makeup items were carried for touch-ups and the frequency of wearing makeup. Majority of the sample began makeup between the ages of 16-19 years. Whilst about $48 \%$ of the sample were against wearing makeup in public and to lecture, almost $52 \%$ vouched for wearing makeup to 'other social situations', (41.4\%) 'job interviews', (60\%) 'on a date' and also believed that makeup enhanced their self-appearance. Moreover, nearly $56 \%$ were satisfied with their overall face features 'without makeup' compared to 'with makeup'. Whereas a significant difference existed amongst those satisfied with their overall face features without makeup, the opposite was the case for those with makeup. In general, $70 \%$ of the respondents were aware of the effects of makeup cosmetics and over $70 \%$ believed that it could have negative effect on the user's skin.

It could be gleaned from the findings that the makeup lifestyles of the Ghanaian female youths under consideration generally differ from similar studies by Korichi et al. (2008), Britton (2012), and Verbakaite (2017). In this study, drawing on the makeup items used, the duration of their application, and frequency of touch ups among others, suggest that in most cases, majority of the female youth use light makeup in all the various makeup circumstances discussed. This might be due to the geographical factors prevalent in the areas they live and other associated demographic factors.

This study is the first to have been carried out in Ghana and therefore presupposes that there are more areas yet to be explored. Future study could consider important areas like: 'makeup lifestyle among the middle age group'; 'makeup lifestyles among the female media personnel and celebrities in Ghana'; 'the negative effects of makeup on Ghanaian women' and 'the contribution of makeup to the movement of fashion in Ghana'.

\section{Recommendation}

It is important that Makeup users are educated on the negative effects of colour cosmetics so that they would be better informed in their application.

\section{Limitation}

Generalizability of the findings is limited to only the study areas due to the use of the nonprobability sampling technique.

\section{References}

Buegeler C. (2015), "Makeup, Your Mind: Social Expectations and Perceptions of Makeup Use", available at bir.brandeis.edu/bitstream/handle/10192/30533/BuegelerThesis2015.pdf?...1...y (Assessed February 26, 2019).

Cash T. F., \& Cash D. W. (1982), “Women's Use of Cosmetics: Psychological Correlates and Consequences”. 
International Journal of Cosmetic Science 4: 1-14. (Assessed February 26, 2019).

Cash, T. F., Dawson, K., Davis, P., Bowen, M. \& Galumbeck, C. (1989), "Effects of Cosmetics Use on the Physical Attractiveness and Body Image of American College Women". The Journal of Social Psychology, 129 (3), 349-355. (Assessed February 26, 2019).

Cash, T. \& Patricia P. E. (1995), "Women's Body Images: The Results of a National Survey in the U.S.A.”. Sex Roles, 33, (1), 19-28, available at https://link.springer.com/article/10.1007/BF01547933 . (Assessed February 26, 2019). Claeyssens, A. (2009), “The History of Cosmetics and Make up," available at http://ezinearticles.com/?The-History-of-Cosmetics-\&- makeup\&id=1857725. (Assessed February 26, 2019).

Ditch the label, (2017), "Your World, Prejudice Free. UK Makeup Shaming. A measure of the pejorative attitudes towards Makeup and those who consume it". In partnership with Sleek Makeup, available at https://www.ditchthelabel.org/wp-content/uploads/2017/.../Makeup-Shaming-UK.pdf (Assessed February 26, 2019)

Dörnyei, Z. (2007), "Research Methods in Applied Linguistics". New York: Oxford University Press.

Etcoff, N. L., Stock, S., Harley, E., Vickery, S. A. \& House, D. M. (2011), "Cosmetics as a Feature of the Extended Human Phenotype: Modulation of the Perception of Biologically Important Facial Signals". PLoS ONE, 6 (10), e 25656.doi10.1371/journal.pone. 0025656.

Fraenkel, J. R. \& Wallen, N. E. (2003), How to Design and Evaluate Research in Education, (5th Ed.). New York, McGraw-Hill Higher Education.

Frevert T. K. \& Walker L. S. (2014), "Physical Attractiveness and Social Status". Sociology Compass Vol. 8 No.3, pp. 313-323, available at https://onlinelibrary.wiley.com/doi/abs/10.1111/soc4.12132. (Assessed 15 May 2019).

Guéguen, N. \& Lamy, L. (2013), "The Effect of Facial Makeup on the Frequency of Drivers Stopping for Hitchhikers". Psychol Rep., 113 (1), 1109-13, available at https://www.ncbi.nlm.nih.gov/pubmed/23484341. (Assessed February 26, 2019).

Guthrie, M., Kim H. \& Jung J. (2008), “The Effects of Facial Image and Cosmetic Usage on Perceptions of Brand Personality". Journal of Fashion Marketing and Management 12 (2), 164-181, Emerald Group Publishing Limited 1361-2026 DOI 10.1108/13612020810874863.

Hinton, P.R. (2004), “Statistics Explained”. 2nd edition. Routledge, London and New York.

https://en.wikipedia.org/wiki/Primer (cosmetics). (Assessed 15 May 2019).

https://m.dailyhunt.in/news/india/english/curejoy-epaper-curejoy/10+harmful+side+effects+of+makeup-newsid66029881. (Assessed 4 July 2019).

http://www.historyofcosmetics.net/cosmetics-facts/types-of-cosmetics/. (Assessed 15 May 2019).

https://paawanee.wordpress.com/2015/03/02/what-factors-to-consider-when-applying-make-up/ (Assessed 15 May 2019).

https://www.scienceofpeople.com/makeup/. (Assessed 15 May 2019).

Isaac, S. \& Michael, W.B. (1995), "Handbook in Research and Evaluation". San Diego, CA, Edits Publishers, available at https://psycnet.apa.org/record/1995-98981-000 (Assessed 15 May 2019).

Jablonski, N. G. (2006), "Skin: A Natural History”. Berkeley, CA: University of California Press

Jones, A., Russell, R., \& Ward, R. (2015), "Cosmetics Alter Biologically-Based Factors of Beauty: Evidence from Facial Contrast”. Evolutionary Psychology, 13, 210-219. doi: 10.1177/147470491501300113. (Assessed 15 May 2019).

Jung, J. \& Lennon, S. (2003), "Body Image, Appearance Self-Schema, and Media Images”. Family and Consumer Sciences Research Journal, 32 (1) 27-51, available at

https://www.academia.edu/.../Body_Image_Appearance_Self-Schema_and_Media_Im... 10.1177/1077727X03255900. (Assessed 12 May 2019).

Kobayashi, Y., Matsushita, S. \& Morikawa, K. (2017), "Effects of Lip Color on Perceived Lightness of Human Facial Skin”. I-Perception 1-10, DOI: 10.1177/2041669517717500. (Assessed 15 March, 2019).

Korichi R., Pelle-De-Queral, D., Gazano, G. \& Aubert A. (2008), "Why Women Use Makeup: Implication of Psychological Traits in Makeup Functions". Journal of Cosmetics Science 59, 127-137, available at https://www.semanticscholar.org/...Korichi-Pelle-de-Queral/548e23658e3c0ab9f38b640... (Assessed 15 March, 2019).

Lavrakas, P. (2008), "Cross-Sectional Survey Design In: Encyclopedia of Survey Research Methods” available at: http://dx.doi.org/10.4135/9781412963947.n120. (Assessed 13 March, 2019).

Leder, H., Mitrovic, A. \& Goller, J. (2016), "How Beauty Determines Gaze! Facial Attractiveness and Gaze Duration in Images of Real World Scenes", i-Perception, (1)12, doi: 10.1177/2041669516664355. (Assessed 13 March, 2019).

Lee, M., Han J. \& Kim E. (2018), “An Evaluation of the Effects of Makeup on Perceived Age Based on Skin Color in Korean Women". J Cosmet Dermatol. doi: 10.1111/jocd.12811 available at 
https://www.ncbi.nlm.nih.gov/pubmed/30407724. (Assessed 23 May, 2019).

Matsushita, S., Morikawa, K. \& Yamanami, H. (2015), "Measurement of Eye Size Illusion Caused by Eyeliner, Mascara, and Eye Shadow". Journal of Cosmetic Science, 66,161-174, available at https://pdfs.semanticscholar.org/a6cc/38100e4e5a679d920f2fe427d604557b6237.pdf. (Assessed 14 February 2019).

Mulbern R., Fieldman G., Hussey T., Leveque J.-L., Pineau P. (2003), “Do Cosmetics Enhance Female Caucasian Facial Attractiveness"? International Journal of Cosmetic Science 25,199-205, available at https://www.ncbi.nlm.nih.gov/pubmed/18494902. (Assessed 14 February, 2019).

Narang, D. (2013), "The Psychological Factors that Affect Makeup Usage and the Perception of Makeup in Different Situations". Proceedings of the National Conference on Undergraduate Research (NCUR), pp. 915918, available at www.ncurproceedings.org/ojs/index.php/NCUR2013/article/view/666. (Assessed 14 February, 2019).

Nash, R., Fieldman G., Hussey T., Leveque J.-L \& Pineau, P. (2006), "Cosmetics: They Influence More Than Caucasian Female Facial Attractiveness". Journal of Applied Social Psychology 36, (2) 493-504, available at https://onlinelibrary.wiley.com/doi/abs/10.1111/j.0021-9029.2006.00016.x. (Assessed 15 April, 2019).

Ogilive, M. \& Ryan M, M. (2011), "Lipstick; More than Fashion Trend”. Research Journal of Social Science and Management, $\quad 1 \quad$ (6), $117-128, \quad$ available https://pdfs.semanticscholar.org/5166/2c4660dbdffb647a58d0c5c13b6ea8856daa.pdf. (Assessed 15 April, 2019).

Russell, R. (2003), "Sex, Beauty, and the Relative Luminance of Facial Features”. Perception, 32, 1093-1107, available https://scholar.google.com/scholar?hl=en\&as_sdt=0\%2C5\&q=Sex $\% 2 \mathrm{C}+$ beauty $\% 2 \mathrm{C}+$ and + the + relative + lu minance + of + facial + features\&btnG $=$. (Assessed 15 April, 2019).

Russell, R. (2010), "Why Cosmetics Work". In R. B. Adams, A. Ambady, K. Nakayama, \& S. Shimojo (Eds.). The science of social vision pp. 186-204). Oxford: Oxford University Press, available at https://scholar.google.com/scholar?hl=en\&as_sdt=0\%2C5\&q=Why+cosmetics+work\&btnG. (Assessed 15 April, 2019).

Russell, R., Batres, C., Courreges, S., Kaminski, G., Soppelsa, F., Morizot, F. \& Porcheron, A. (2018), "Differential Effects of Makeup on Perceived Age". British Journal of Psychology, available at www.researchgate.net/publication/326812073_Differential_effects_of_makeup_on_perceived_age. (Assessed 17 May, 2019).

Singh, S. K. (2010), "Handbook on Cosmetics (Processes, Formulae with Testing Methods)". Asia Pacific Business Press Inc, available at https://www.niir.org/books/book/handbook-on-cosmetics-processesformulae-with-testing-methods/isbn-9788178331294/zb,,16f,a,2b,0,3e8/index.html. (Assessed 18 May, 2019).

Stephen, I. D. \& McKeegan, A. M. (2010), "Lip Colour Affects Perceived Sex Typicality and Attractiveness of Human Faces". Perception, Vol. 39, pp. 1104-1110, available at https://scholar.google.com/scholar?hl=en\&as_sdt=0\%2C5\&q=Lip+colour+affects+perceived+sex+typicalit

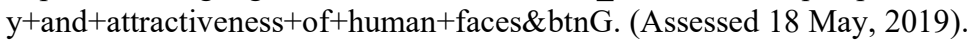

Stuart, A. \& Donaghue, N. (2011), "Choosing to Conform: The Discursive Complexities of Choice in Relation to Feminine Beauty Practices". Feminism and Psychology, 22, 98-121, available at https://scholar.google.com/scholar?hl=en\&as_sdt=0\%2C5\&q=Choosing +to+Conform $\% 3 \mathrm{~A}+\mathrm{The}+$ discursive +Complexities+of+choice+in+relation+to+feminine+beauty+practices\&btnG. (Assessed 18 May, 2019).

Verbickaite G. (2017), "What is the Impact of the Cosmetic Industry in the West on Caucasian Female Consumer Wellbeing"? available https://scholar.google.com/scholar?hl=en\&as_sdt=0\%2C5\&q=What + is + the + Impact + of + the + Cosmetic + Ind ustry+in+the + West + on+Caucasian+Female + Consumer+Wellbeing\&btnG. (Assessed 13 March, 2019). 